\title{
A review of trauma deaths in an accident and emergency department
}

\author{
T. J. UNDERHILL* \& B. J. FINLAYSON $\dagger$
}

Accident and Emergency Department, *Derbyshire Royal Infirmary, Derby and $\dagger$ Norfolk $\rightarrow$ and Norwich Hospital, Norwich, England

\section{SUMMARY}

There were 56 deaths following trauma in the adult Accident and Emergency Depart-9 ment of the University Hospital, Nottingham, over a 5-year period from 1983 to 1987. Forty-six of these deaths followed road-traffic accidents.

The trauma deaths made up $16 \%$ of all adult deaths and 0.13 per thousand newattenders. We found evidence of inappropriate management in four cases, all relating to inadequate volume replacement. In two patients, the degree of hypovolaemia was appreciated and in the other two, volume replacement was not commenced withing 30 min of arrival in the department.

Prompt treatment of hypovolaemic shock with appropriate fluids in adequate⿳⺈ quantities cannot be overemphasized.

\section{INTRODUCTION}

There has recently been much controversy over the standards of care offered to trauma victims in the UK (Mason M. A., 1987). In view of this, we reviewed the post-mortemo findings and the case notes of all the patients who died in the adult Accident andङ Emergency Department at the University Hospital, Nottingham, or en route to anothero ward, following trauma, over a 5-year period from 1983 to 1987.

The department saw 82000 new adult patients in 1983, rising to 91000 in 1985 and응. falling to 87000 in 1987 . The department is the only accident unit serving the city of o Nottingham and surrounding area, with a catchment population of 820000 .

The department is staffed by three consultants (two until June 1987), one seniorn registrar, two registrars and 12 senior house officers. Out-of-hours senior covero

Correspondence: Mr T.F. Underhill, Senior Registrar, Accident and Emergency Department, Derbyshire Royal Infirmary, London Road, Derby DE1 2QY, England. 
(registrar or senior registrar) is present in the department from $1700 \mathrm{~h}$ to $0200 \mathrm{~h}$ or later, and is available at short notice from $0200 \mathrm{~h}$ until $0900 \mathrm{~h}$.

Our survey includes all the patients who were brought into the department by the emergency services, although with the benefit of hindsight it is clear that some of them died in transit.

There were 56 patients in all, 33 male and 23 female. The average age of the male patients was 34.8 years, and of the female patients, 60.5 years.

The aim of this survey was to identify from post-mortem reports any areas in which the management of trauma patients was less than optimal, and to suggest any measures that might improve the standard of care offered to trauma patients within the emergency department.

\section{METHODS}

The road-traffic accident related deaths were divided into car occupant, pedestrian and motor-cycle; the non-road traffic deaths were divided into falls, crush injuries and sport-related. All the adult patients who died in the accident and emergency department or within $6 \mathrm{~h}$ of transfer out of the department had post-mortem examinations. We reviewed these reports, in conjunction with the case notes, to determine any discrepancy in diagnosis and possible mismanagement.

Each patient was assigned an injury severity score from the post-mortem reports, in accordance with the 1980 revision of the Abbreviated Injury Scale (Baker et al., 1974; American Association for Automotive Medicine, 1980).

The injury severity scores were compared with the so-called 'LD 50' injury scores. The 'LD 50' injury score was devised to relate injury severity score to age and represents the score at which there is a predicted mortality of $50 \%$ for a given age range (Bull, 1975) (Table 1).

This relationship between age, injury severity score and predicted mortality was derived from a retrospective study of 1333 inpatients treated in the Birmingham Accident Hospital, and a similar relationship was found in a study in Baltimore, USA in a study of 2128 patients (Baker \& O'Neill, 1976).

Table 1 'LD 50' scores

\begin{tabular}{cc}
\hline Age range & $\begin{array}{c}\text { Injury severity } \\
\text { score }\end{array}$ \\
\hline $15-44$ & 40 \\
$45-64$ & 29 \\
Over 65 & 20 \\
\hline
\end{tabular}


Table 2 Mechanisms of injury

\begin{tabular}{lcc}
\hline & Male & Female \\
\hline Road-traffic accidents & 7 & 13 \\
Pedestrian & 16 & 6 \\
Car occupant & 3 & 1 \\
Motor-cycle & & \\
Non-road traffic accidents & 3 & 3 \\
Falls & 3 & 0 \\
Crush & 1 & 0 \\
Sports & &
\end{tabular}

\section{RESULTS}

There were 56 adult trauma deaths during the study period, 33 males and 23 females. This represents $16 \%$ of all adult accident and emergency deaths (350) during this period, and $0.013 \%$ of all new adult presentations to the department (438 333). Table $2 \frac{c}{5}$ shows the mechanisms of injury, and Table 3 the age ranges.

From Table 2 it may be seen that 46 out of the 56 trauma deaths were as a result of $\vec{\varnothing}$ road-traffic accidents. We also noted that the majority of car occupants were young $\bullet$ men, whereas most of the pedestrian deaths were middle-aged or elderly women. Of the patients who died following falls, three were from a considerable height (one $\frac{9}{9}$ deliberate suicide), two were in the $80+$ age group who fell downstairs at home, both sustaining head injuries with subdural haemorrhage, and one was an elderly patient who died from haemorrhage after falling through a glass window (patient 2, Table 6).

Table 3 Trauma deaths and all accident and emergency deaths by age

\begin{tabular}{lrcrc}
\hline & \multicolumn{2}{c}{ Trauma deaths } & & \multirow{2}{*}{ All deaths } \\
\cline { 1 - 3 } Ages & Male & Female & Total & \\
\hline $10-19$ & 4 & 1 & 5 & 5 \\
$20-29$ & 15 & 2 & 17 & 22 \\
$40-49$ & 4 & 1 & 5 & 28 \\
$50-59$ & 3 & 4 & 7 & 40 \\
$60-69$ & 2 & 5 & 7 & 85 \\
$70-79$ & 2 & 3 & 5 & 112 \\
$80+$ & 1 & 5 & 6 & 39 \\
Total & 33 & 23 & 56 & 350 \\
\hline
\end{tabular}


Table 4 displays the numbers of patients in each age group with injury severity scores greater or less than the 'LD 50' scores for these ages (NB a score of 75-the maximum possible in the scoring system used-indicates certain death). Those patients listed as dead on arrival were certified dead within $10 \mathrm{~min}$ of arrival in the department, and had shown no vital signs. Of the 46 patients who arrived in the department alive, 17 had fatal injuries with injury severity scores of 75,24 had a greater than $50 \%$ probability of dying and five arrived alive with injuries that were survivable, with injury severity scores less than the 'LD 50' values for their age groups. The details of these patients are shown in Table 5. We also identified two cases which were, in our opinion, inappropriately managed in the group of patients who were alive on arrival, with an injury severity score greater than the 'LD 50' (Table 6).

\section{DISCUSSION}

Two previous surveys of deaths in accident and emergency departments in the UK (Shalley \& Cross, 1984; Beckett et al., 1987) have included deaths from all causes. The London survey found that trauma deaths made up $13 \%$ of the total deaths occurring in three departments during one year and this is similar to our figure of $16 \%$ over a 5 -year period. In the Birmingham survey only $5 \%$ of 488 deaths over a 5 -year period were due to trauma. Following recent controversy in the press, we concentrated our study on deaths due to trauma to try to find out whether criticisms aimed at the trauma services in the UK were justified with respect to the Accident and Emergency Department in Nottingham.

It is difficult to define what constitutes death in the accident and emergency department. Patients who die in transit from the scene of the accident are often brought into the department by ambulance crews in the hope that they might be resuscitated, only to be certified dead shortly after arrival. These patients have been included in our study, and classified as 'Dead on arrival'. Other problems exist when patients leave the department alive, only to die within a few hours. Although strictly not accident and emergency deaths, their condition at this stage would depend a great deal on the management they received in the department. We have therefore included deaths occurring up to $6 \mathrm{~h}$ after leaving the department.

We have identified five patients who had injury severity scores lower than the 'LD 50' scores for their ages, and who therefore had a greater than $50 \%$ likelihood of survival, but who died nevertheless (Table 5). Two of these left the department alive and died during or immediately after operation, and there was no evidence of suboptimal care at any stage. With reference to the three who died in the department, there was a delay in instituting adequate fluid resuscitation in two patients, either due to difficulty of access (patient 4), or because the extent of hypovolaemia was not recognized (patient 2). The two cases of inappropriate management in patients not expected to survive (Table 6 ) were also due to a failure to recognize hypovolaemia early and to treat it adequately.

The difficulties involved in getting adequate radiographs in severely injured patients occur in many departments throughout the country and there is often pressure on junior staff to take patients out of the resuscitation room to the X-ray department to avoid 
Table 4 Injury severity score related to 'LD 50'

\begin{tabular}{lcccrrr}
\hline Age range & \multicolumn{2}{c}{$\begin{array}{c}\text { ISS }<\text { 'LD 50' } \\
\text { AOA* }\end{array}$} & $\begin{array}{c}\text { ISS }>\text { 'LD 50' } \\
\text { AOA }\end{array}$ & DOA & AOA & ISS 75 \\
\hline $15-44$ & 4 & 0 & 9 & 3 & 8 & 4 \\
$45-64$ & 0 & 1 & 5 & 0 & 7 & 1 \\
Over 65 & 1 & 0 & 10 & 0 & 2 & 1 \\
Total & 5 & 1 & 24 & 3 & 17 & 6 \\
\hline
\end{tabular}

*AOA $=$ Alive on arrival.

+ DOA $=$ Dead on arrival.

Table 5 Analysis of patients with ISS < 'LD 50'

\begin{tabular}{|c|c|c|c|c|c|}
\hline Patient no. & Sex & Age & Mechanism & ISS & Comment \\
\hline 1 & $\mathbf{M}$ & 30 & RTA & 24 & $\begin{array}{l}\text { Multiple injuries*. Died in theatre } \\
173 \text { min post-admission. }\end{array}$ \\
\hline 2 & $\mathbf{M}$ & 80 & Fall & 4 & $\begin{array}{l}\text { Multiple lacerations } \dagger \text {. Degree of } \\
\text { haemorrhage not appreciated. }\end{array}$ \\
\hline 3 & $\mathbf{M}$ & 20 & RTA & 34 & $\begin{array}{l}\text { Multiple injuries**. Cardiorespirator } \\
\text { arrest in X-ray. }\end{array}$ \\
\hline 4 & $\mathbf{M}$ & 28 & RTA & 38 & $\begin{array}{l}\text { Multiple injuries } \dagger \dagger \text {. Grossly obese. } \\
\mathrm{I}-\mathrm{V} \text { access not achieved for } 30 \mathrm{~min} \text {. }\end{array}$ \\
\hline 5 & $\mathbf{M}$ & 22 & RTA & 38 & $\begin{array}{l}\text { Multiple injuriesł. Died post- } \\
\text { operatively in ITU. }\end{array}$ \\
\hline
\end{tabular}

*Ruptured spleen, bilateral multiple rib fractures, haemopneumothorax.

†External lacerations. No internal injury or major vessel.

** $\mathrm{C} 1 / \mathrm{C} 2$ subluxation, retroperitoneal haemorrhage, retromediastinal haemorrhage.

$\dagger \dagger$ Multiple rib fractures, multiple pelvic fractures, fractured femur.

$\ddagger_{\ddagger}$ Multiple rib fractures, ruptured spleen, ruptured kidney, fractured humerus.

Table 6 Analysis of patients with ISS > 'LD 50' with inappropriate management

\begin{tabular}{|c|c|c|c|c|c|}
\hline Patient no. & Sex & Age & Mechanism & ISS & Comment \\
\hline 1 & $\mathbf{F}$ & 67 & RTA & 34 & $\begin{array}{l}\text { Multiple injuries. Avoidable delay of } \\
40 \mathrm{~min} .\end{array}$ \\
\hline 2 & $\mathbf{F}$ & 24 & RTA & 50 & $\begin{array}{l}\text { Multiple injuries. Delay in diagnosis } \\
\text { of intra-abdominal haemorrhage. }\end{array}$ \\
\hline
\end{tabular}


portable X-rays. Two patients in our survey (patient 3, Table 5 and another male aged 24, ISS 41) suffered cardiorespiratory arrests in the X-ray department. Some departments are equipped with full radiological facilities in the resuscitation room, but until this facility becomes more widespread, it is inevitable that patients with multiple injuries will require portable X-rays in the initial stages of management. Only when the patient's condition is stable should they be moved out of the resuscitation room for the less urgent radiographs to be taken.

The importance of senior cover in the emergency department was clearly illustrated by Dearden \& Rutherford (1985) in whose department over $50 \%$ of severely injured patients were seen by a junior house officer. In Nottingham, all seriously injured patients are seen by a more experienced doctor, day or night, either in a supervisory role, or as the 'primary doctor'. We believe that this is not only in the best interests of the patients, but also the best method of teaching resuscitation techniques to the casualty officers.

\section{CONCLUSION}

We have identified four cases in this 5-year study of trauma deaths in which adequate fluid resuscitation was delayed. Two patients had an ISS of less than the 'LD 50' for their age, and their deaths might have been avoided. It would appear that there is a danger of underestimating the extent of hypovolaemia in trauma patients. Pulse rate and blood pressure are unreliable as measures of hypovolaemia, and indicators of tissue perfusion such as venous filling and skin temperature are more accurate (Ramsay, 1988). Elderly patients have a reduced capacity to compensate for fluid loss and may become shocked following relatively minor injuries.

Ideally hypovolaemic shock in patients with multiple injuries requires volume replacement with blood, and we agree with Shalley \& Cross (1984) that blood transfusions started earlier and given more rapidly might save lives. In practice, however, initial volume replacement is with either crystalloid or colloid, and there appears to be little to choose between them (Yates, 1984; Ramsay, 1988); of far greater importance is the speed with which an adequate volume can be infused into the patient.

We suggest that a greater awareness of this problem, and a more aggressive approach to its treatment, would be one way in which accident and emergency departments could improve the standard of care offered to trauma victims.

\section{ACKNOWLEDGEMENTS}

The authors wish to thank the consultants in the Accident and Emergency Department, University Hospital, Nottingham, namely Dr S. H. Dave, Dr A. F. Dove and Mr L. Jarrett for their encouragement in carrying out this study, and for allowing access to records. 


\section{REFERENCES}

American Association for Automotive Medicine (1980) The Abbreviated Injury Scale, 1980 revision. Morton 3 Grove, AAAM.

Baker S. P., O’Neill B., Hadden W. \& Long W. B. (1974) The injury severity score: a method for describing: patients with multiple injuries and evaluating emergency care. Fournal of Trauma 14, 187-96.

Baker S. P. \& O'Neill B. (1976) The injury severity score: an update. Fournal of Trauma 16, 882-5.

Beckett M. W., Longstaff P. M., McCabe M. J., Sulch D. A. \& Ward M. J. (1987) Deaths in three accident and emergency departments. Archives of Emergency Medicine 4, 227-32.

Bull J. P. (1985) The ISS of road traffic casualties in relation to mortality, time of death, hospital treatment官 time and disability. Accident Analysis and Prevention 7, 249-55.

Dearden C. H. \& Rutherford W.H. (1985) The resuscitation of the severely injured in the accident and emergency department-a medical audit. Injury 16, 249-52.

Mason M. A. (1987) Editorial. British fournal of Accident and Emergency Medicine 2, 4, 3.

Ramsay G. (1988) Intravenous volume replacement: indications and choices (Leading article). British $\vec{\omega}$ Medical fournal 296, 1422-3.

Shalley M. J. \& Cross A. B. (1984) Which patients are likely to die in an accident and emergency department? British Medical fournal 289, 419-21.

Yates D.W. (1984) A review of commonly used replacement fluids. Archives of Emergency Medicine 100 (Supplement), 1-8. 